\title{
Concomitant surgical closure of left atrial appendage: A systematic review and meta-analysis
}

\author{
Masahiko Ando, MD, PhD, MPH, Masaki Funamoto, MD, Duke E. Cameron, MD, and
}

Thoralf M. Sundt III, MD

\section{ABSTRACT}

Objectives: Although percutaneous closure of the left atrial appendage is supported as a potential alternative to lifelong anticoagulation in patients with atrial fibrillation, comprehensive evidence on surgical left atrial appendage closure in heart surgery is limited.

Methods: We conducted a meta-analysis of studies comparing patients who underwent open cardiac surgery with or without left atrial appendage closure. A literature search was performed on PubMed, Embase, and Cochrane Trials databases. Outcomes of interest were 30-day/in-hospital mortality and cerebrovascular accident. $\mathrm{I}^{2}$ statistics were used to evaluate heterogeneity, and publication bias was evaluated by Begg's and Egger's tests.

Results: We reviewed 1284 articles and selected for main analysis 7 articles including 3897 patients (1963 in the left atrial appendage closure group and 1934 in the non-left atrial appendage closure group). Among the 7 studies, 3 were randomized-controlled studies, 3 were propensity-matched studies, and 1 was a case-matching study. At 30-day/in-hospital follow-up, left atrial appendage closure was significantly associated with decreased risk of mortality and cerebrovascular accident (odds ratio, 0.384, 95\% confidence interval, 0.233-0.631 for mortality, and odds ratio, 0.622 , 95\% confidence interval, 0.388-0.998 for cerebrovascular accident). Stratified analysis demonstrated that this association was more prominent in preoperative atrial fibrillation strata.

Conclusions: Concomitant surgical left atrial appendage closure should be considered at the time of open cardiac surgery, particularly among those in atrial fibrillation preoperatively. The benefit of left atrial appendage closure for patients not in atrial fibrillation and for those undergoing nonvalvular surgery is still unclear. Further prospective investigations are indicated. (J Thorac Cardiovasc Surg 2018;156:1071-80)

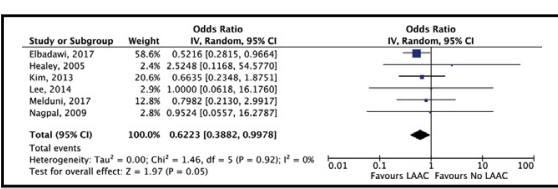

LAAC was associated with a reduced odds of early CVA (odds ratio, 0.622; 95\% Cl, 0.388-0.998).

\section{Central Message}

Surgical LAAC was associated with lower mortality/CVA, especially in AF strata. This tendency was also observed in valve surgery strata. The benefit of LAAC in non-AF/ nonvalvular cases is still unclear.

\section{Perspective}

Although percutaneous closure of LAA for patients with $\mathrm{AF}$ is a prevailing topic in cardiology, evidence of the value of surgical LAAC is limited. This meta-analysis showed better early survival and lower CVA, especially in preoperative $\mathrm{AF}$ cohorts, with surgical LAAC. Given the increase in the population with $\mathrm{AF}$, our findings support further studies for those who might benefit from this procedure.

See Editorial Commentaries pages 1081 and 1083.

See Editorial page 1069.
Although percutaneous closure of the left atrial appendage (LAA) is supported as a potential alternative to lifelong anticoagulation for stroke prophylaxis in patients with atrial fibrillation (AF), ${ }^{1-4}$ comprehensive evidence on surgical LAA closure (LAAC) at the time of cardiac surgery is limited. In contrast to percutaneous LAAC, concomitant surgical LAAC is most often secondary to the main cardiac procedure. Anecdotal risks associated with LAAC

\footnotetext{
From the Division of Cardiac Surgery, Massachusetts General Hospital and Harvard Medical School, Boston, Mass.

Received for publication April 28, 2017; revisions received Dec 8, 2017; accepted for publication March 2, 2018; available ahead of print April 6, 2018.

Address for reprints: Masahiko Ando, MD, PhD, MPH, Massachusetts General Hospital, 55 Fruit St, Boston, MA 02114. (E-mail: mandou-tky@umin.ac.jp). $0022-5223 / \$ 36.00$

Copyright (c) 2018 by The American Association for Thoracic Surgery https://doi.org/10.1016/j.jtcvs.2018.03.017
}

itself, such as bleeding or coronary artery injury, are reportedly low, ${ }^{5}$ and ongoing development of staplers or other devices for this purpose ${ }^{6}$ may reduce these risks further, although at some expense. There is increasing interest in the surgical community in adding LAAC, especially for patients with preoperative AF or mitral valve disease. However, there have been no large randomized surgical trials on this topic published thus far. Currently available reports are based only on small randomized trials

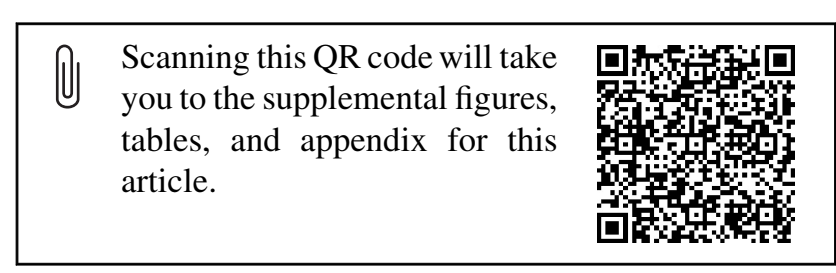




$$
\begin{aligned}
& \text { Abbreviations and Acronyms } \\
& \begin{aligned}
\text { AF } & =\text { atrial fibrillation } \\
\text { CABG } & =\text { coronary artery bypass grafting } \\
\text { CI } & =\text { confidence interval } \\
\text { CVA } & =\text { cerebrovascular accident } \\
\text { LAA } & =\text { left atrial appendage } \\
\text { LAAC } & =\text { left atrial appendage closure } \\
\text { OR } & =\text { odds ratio } \\
\text { PSM } & =\text { propensity-score matched } \\
\text { RCT } & =\text { randomized controlled trial }
\end{aligned}
\end{aligned}
$$

or medium-sized observational studies, which have failed to demonstrate a clear benefit or risk of concomitant surgical LAAC. Accordingly, no clear consensus has been established on whether we should add surgical LAAC or not during cardiac surgery. Moreover, given the increasing prevalence of AF among those who undergo heart surgery, ${ }^{7}$ as well as in the general population, ${ }^{8}$ the number of patients who might appreciate benefits or incur risks from surgical LAAC may increase in the future. Therefore, we undertook the present systematic review and meta-analysis aimed to investigate outcomes after surgical LAAC, focusing on risk of mortality and cerebrovascular accident (CVA).

\section{MATERIALS AND METHODS}

The present study was conducted in accordance with the Preferred Reporting Items for Systematic Reviews and Meta-Analyses statement ${ }^{9}$ and the recommendations from the Cochrane Collaboration and Meta-analysis of Observational Studies in Epidemiology. ${ }^{10}$ Each included study was approved by an institutional review committee.

\section{Literature Search}

A literature search was performed on the basis of Ovid Medline (PubMed), Embase, and Cochrane Central Register of Controlled Trials databases for studies incorporated into these databases from their date of inception to December 2016. The specific terms "surgery" and "atrial appendage" were included in the literature search to maximize the sensitivity of article search. Detailed search terms are provided in the Supplementary Data. We also located studies via personal communication with experts in the field. The reference lists of all the articles included in our analysis and the previous systematic reviews and meta-analyses were also reviewed for potentially additional articles.

\section{Study Selection and Data Extraction}

To be included, the studies had to be a randomized controlled trial (RCT), propensity-score matched (PSM) study, case-matching study, or observational cohort study comparing the population who underwent LAAC in cardiac surgery with the population who did not. Unadjusted cohort studies were pooled separately from RCTs or adjusted studies, and single-arm studies were excluded. The outcomes of interests were 30-day or in-hospital mortality and CVA. All open cardiac surgical procedures including coronary artery bypass grafting (CABG) and valve surgery were included. All publications were limited to human subjects and in the English language. Abstracts, case reports, conference presentations, editorials, and expert opinions were excluded. Review articles were omitted because of potential publication bias and possible duplication of results. This process of study selection and reasons for exclusion are summarized in Figure 1. A total of 7 studies (RCTs or matching studies) (Table 1) were included in the main analysis, and 2 of them had not been incorporated in the previous meta-analyses. ${ }^{18}$

From each study, the following information was extracted from article texts, tables, and figures: the odds ratios (ORs) for early mortality and CVA with their $95 \%$ confidence intervals (CIs), the first author's last name, publication year, country of the study cohort, sample size, number of cases, follow-up period, study design, patient population, exclusion criteria, LAAC closure technique, mean age, male percentage, preoperative $A F$ percentage, and valve surgery percentage (Table 1). When insufficient data were available from publications, corresponding authors were contacted to provide additional records. Two investigators (MA and MF) independently reviewed each retrieved article. Discrepancies between the 2 reviewers were resolved by discussion and consensus.

\section{Statistical Analysis}

The present meta-analysis was performed by combining all results of reported mortality and CVA. Two separate Forest plots were made to investigate the association between concomitant LAAC and (1) 30-day/ in-hospital mortality and (2) 30-day/in-hospital CVA. As a weighting method for pooled estimates, random-effect model with inverse variance method was used. The OR was used as a summary statistic. Chi-square tests were used to study heterogeneity between trials. The $\mathrm{I}^{2}$ statistic was used to estimate the percentage of total variation across studies, because of heterogeneity rather than chance. An $\mathrm{I}^{2}$ value of greater than $50 \%$ was considered substantial heterogeneity. To evaluate the potential source of heterogeneity across the included studies, stratified meta-analyses were also performed. Stratification factors were preoperative AF dominance ( $>50 \%)$ and valve surgery dominance $(>50 \%)$. To assess the influence of each study on the pooled estimates, we omitted the studies one by one and recalculated the pooled estimates to see how ORs of interest changed by removing each study. Evidence of publication bias was sought using Egger and Begg's methods and Funnel plot if necessary. All $P$ values were 2-sided. All statistical analysis was conducted with Review Manager 5.3 (Cochrane community) and Stata 14.1 (StataCorp, LP, College Station, Tex).

\section{RESULTS}

The initial search identified 1284 articles, including 301 articles from PubMed, 980 from Embase, and 3 from Cochrane Central Register of Controlled Clinical Trials (Figure 1). After removing duplicate articles, we extracted 1033 articles for title and abstract review. Among them, 1008 articles were excluded for the reasons shown in Figure 1, leaving 25 articles for assessment based on full text. Their references were also reviewed for additional publications. After review, 14 publications remained to be included in the current systematic review.,11-17,19-24 Among them, 3 RCTs and 4 adjusted studies were included in the main analysis.

The demographic details in each study are demonstrated in Table 1 and Table E1. A total of 3897 patients were included in the analysis (1963 in the LAAC group and 1934 in the non-LAAC group). Among 7 studies, 3 were randomizedcontrolled, ${ }^{15-17} 3$ were propensity-matched, ${ }^{12-14}$ and 1 was case-matching. ${ }^{11}$ As for patient population, 5 studies included both valve surgery and $\mathrm{CABG},{ }^{11,12,14-16} 1$ study focused on isolated $\mathrm{CABG},{ }^{17}$ and 1 study evaluated ablation for $\mathrm{AF}$ with mitral valve surgery. ${ }^{13}$ 
1284 publications were identified on initial search

- 301 Pubmed

- 980 Embase

- 3 Cochrane Central Register of Clinical Trials

251 duplicates were removed

1033 publications were screened based on title and abstract

1008 publications were excluded for not meeting the inclusion criteria

- 342 Intervention/Percutaneous

- 320 Not relevant

- 91 Minimally invasive surgery

- 105 Study model not appropriate

- 69 Imaging-related

- 36 Not human

- 20 Not English

- 25 Abstract for scientific meeting

25 publications were assessed based on full-text and their references were reviewed for additional publications

18 publications were excluded

- 10 Not sufficient information

- 1 Trial design only

- 7 Unadjusted study design

7 publications, corresponding to 7 studies, were included in analysis

FIGURE 1. Summary of study inclusion and exclusion. 
TABLE 1. Main characteristics of included studies

\begin{tabular}{|c|c|c|c|c|c|c|c|c|c|c|}
\hline First author, $\mathbf{y}$ & Country & $\begin{array}{l}\text { Sample } \\
\text { size }\end{array}$ & $\begin{array}{l}\text { Study } \\
\text { design }\end{array}$ & $\begin{array}{l}\text { Follow-up } \\
\text { period }(\mathbf{m o})\end{array}$ & Patient population & $\begin{array}{c}\text { LAAC } \\
\text { technique }\end{array}$ & $\begin{array}{c}\text { Mean } \\
\text { age, } \\
\mathbf{y}\end{array}$ & Male $\%$ & $\begin{array}{c}\text { Preoperative } \\
\text { AF } \%\end{array}$ & $\begin{array}{c}\text { Valve } \\
\text { surgery } \%\end{array}$ \\
\hline $\begin{array}{c}\text { Elbadawi, } \\
2017^{11}\end{array}$ & United States & 1304 & $\begin{array}{l}\text { Case- } \\
\text { matching }\end{array}$ & 1 & Valve surgery for $\mathrm{AF}$ & Unknown & 71.0 & 54.4 & 100.0 & 100.0 \\
\hline $\begin{array}{l}\text { Melduni, } \\
2017^{12}\end{array}$ & United States & 922 & PSM & 109.2 & Open surgery & $\begin{array}{l}\text { Amputation/ } \\
\text { ligation }\end{array}$ & 67.5 & 62.4 & 46.0 & 96.6 \\
\hline Lee, $2014^{13}$ & Korea & 238 & PSM & $63 \pm 44$ & $\begin{array}{l}\text { MV surgery with } \\
\text { ablation for } \mathrm{AF}\end{array}$ & Amputation & 53.8 & 39.5 & 100.0 & 100.0 \\
\hline Kim, $2013^{14}$ & United States & 1262 & PSM & 1 & Open surgery & $\begin{array}{l}\text { Amputation/ } \\
\text { stapler/ } \\
\text { ligation }\end{array}$ & 66.0 & 68.1 & - & 15.2 \\
\hline $\begin{array}{l}\text { Whitlock, } \\
2013^{15}\end{array}$ & Canada & 51 & $\mathrm{RCT}$ & 1 & $\begin{array}{l}\text { Open surgery with } \\
\text { AF/risk of } \\
\text { embolization }\end{array}$ & $\begin{array}{l}\text { Amputation/ } \\
\text { stapler }\end{array}$ & 76.0 & 76.5 & 100.0 & 41.2 \\
\hline $\begin{array}{l}\text { Nagpal, } \\
2009^{16}\end{array}$ & Italy & 43 & $\mathrm{RCT}$ & $<1$ & MVR or MV repair & $\begin{array}{l}\text { Endocardial } \\
\text { suture }\end{array}$ & 58.5 & 53.5 & 18.6 & 100.0 \\
\hline $\begin{array}{l}\text { Healey, } \\
\qquad 2005^{17}\end{array}$ & Canada & 77 & $\mathrm{RCT}$ & $13 \pm 7$ & $\begin{array}{l}\text { CABG with risk of } \\
\text { AF or embolization }\end{array}$ & $\begin{array}{c}\text { Epicardial } \\
\text { suture/ } \\
\text { stapler }\end{array}$ & 71.7 & 72.7 & 32.5 & 0.0 \\
\hline
\end{tabular}

$L A A C$, Left atrial appendage closure; $A F$, atrial fibrillation; $P S M$, propensity-score matched; $M V$, mitral valve; $R C T$, randomized controlled trial; $M V R$, mitral valve replacement; $C A B G$, coronary artery bypass grafting.

\section{Short-Term Outcomes}

Figure 2, A, shows the OR of 30-day or in-hospital mortality. Among 7 studies, 4 were excluded because we were not able to calculate individual log ORs because of zero mortality in 1 of each group. The point estimate of OR for mortality was lower than 1 (favors LAAC) in all the 3 studies included, and the overall OR was significant, with no significant heterogeneity across the studies (OR, $0.384,95 \%$ CI, 0.233-0.631, $\mathrm{I}^{2} 0.0 \%, P=.646$ ). Figure 2, $B$, shows the OR of 30-day or in-hospital CVA, showing less CVA rates in the LAAC group (OR, 0.622, $95 \%$ CI, 0.388-0.998, $\left.\mathrm{I}^{2} 0.0 \%, P=.917\right)$.

\begin{tabular}{|c|c|c|c|c|c|c|c|c|c|c|c|}
\hline Study or Subgroup & \multicolumn{2}{|c|}{ LAAC } & \multicolumn{2}{|c|}{ No LAAC } & \multicolumn{2}{|r|}{ Odds Ratio } & \multicolumn{5}{|c|}{$\begin{array}{c}\text { Odds Ratio } \\
\text { IV, Random, } 95 \% \mathrm{CI}\end{array}$} \\
\hline Melduni, 2017 & 12 & 461 & 24 & 461 & $49.7 \%$ & $0.4866[0.2404,0.9852]$ & & 7 & & & \\
\hline Lee, 2014 & 0 & 119 & 1 & 119 & $2.4 \%$ & $0.3305[0.0133,8.1961]$ & & & & & \\
\hline Elbadawi, 2017 & 10 & 652 & 32 & 652 & $47.9 \%$ & $0.3018[0.1471,0.6191]$ & & - & & & \\
\hline Total $(95 \% \mathrm{Cl})$ & & 1232 & & 1232 & $100.0 \%$ & $0.3835[0.2333,0.6306]$ & & & & & \\
\hline Total events & 22 & & 57 & & & & & & & & \\
\hline $\begin{array}{l}\text { Heterogeneity: Tau }{ }^{2} \\
\text { Test for overall effec }\end{array}$ & $\begin{array}{l}0.00 ; C r \\
Z=3.7 \varepsilon\end{array}$ & $\begin{array}{l}i^{2}=0 \\
3(P=0\end{array}$ & $\begin{array}{l}87, \mathrm{df}= \\
.0002)\end{array}$ & $2(P=$ & $0.65) ; I^{2}$ & $0 \%$ & 0.01 & $\begin{array}{l}0.1 \\
\text { Favours LAAC }\end{array}$ & 1 Favours N & $\begin{array}{l}10 \\
\text { No LAAC }\end{array}$ & 100 \\
\hline
\end{tabular}

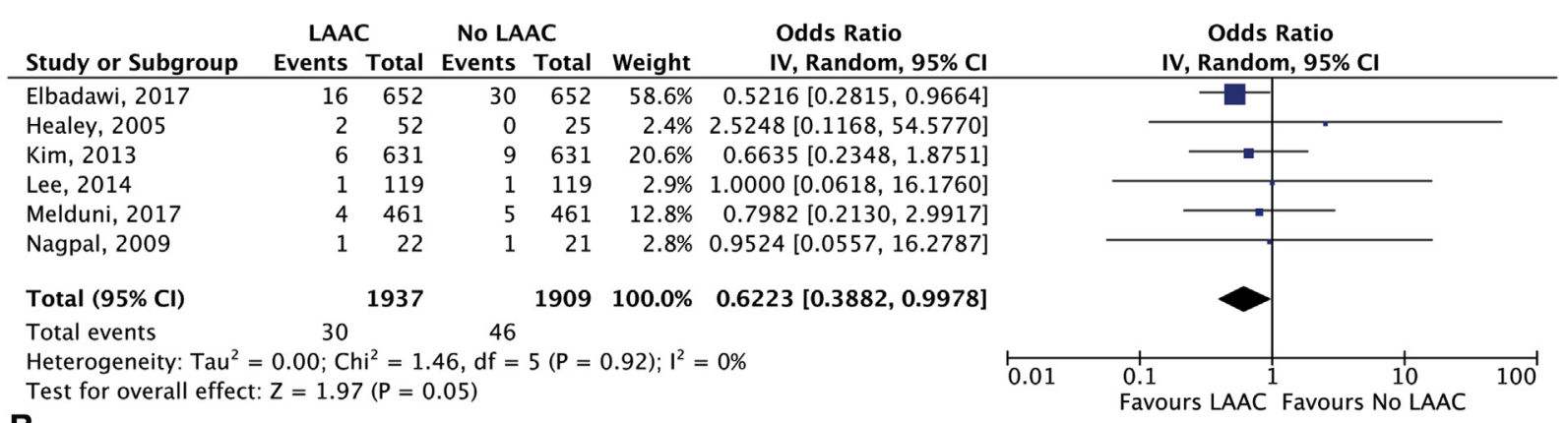

FIGURE 2. Thirty-day or in-hospital mortality (A) and 30-day or in-hospital CVA (B) in randomized trials and matching studies. LAAC, Left atrial appendage closure; $I V$, inverse variance; $C I$, confidence interval. 


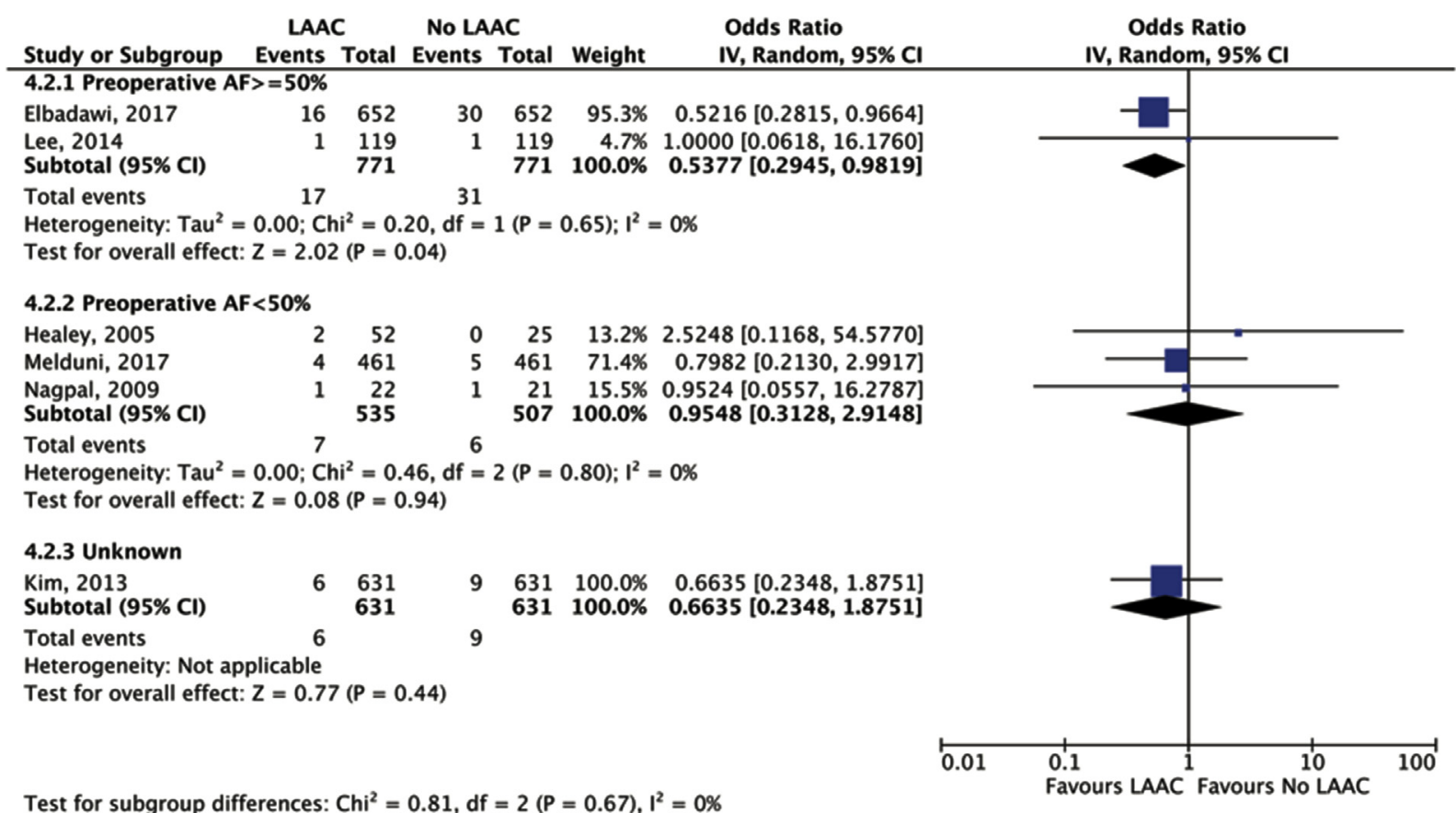

\section{A}

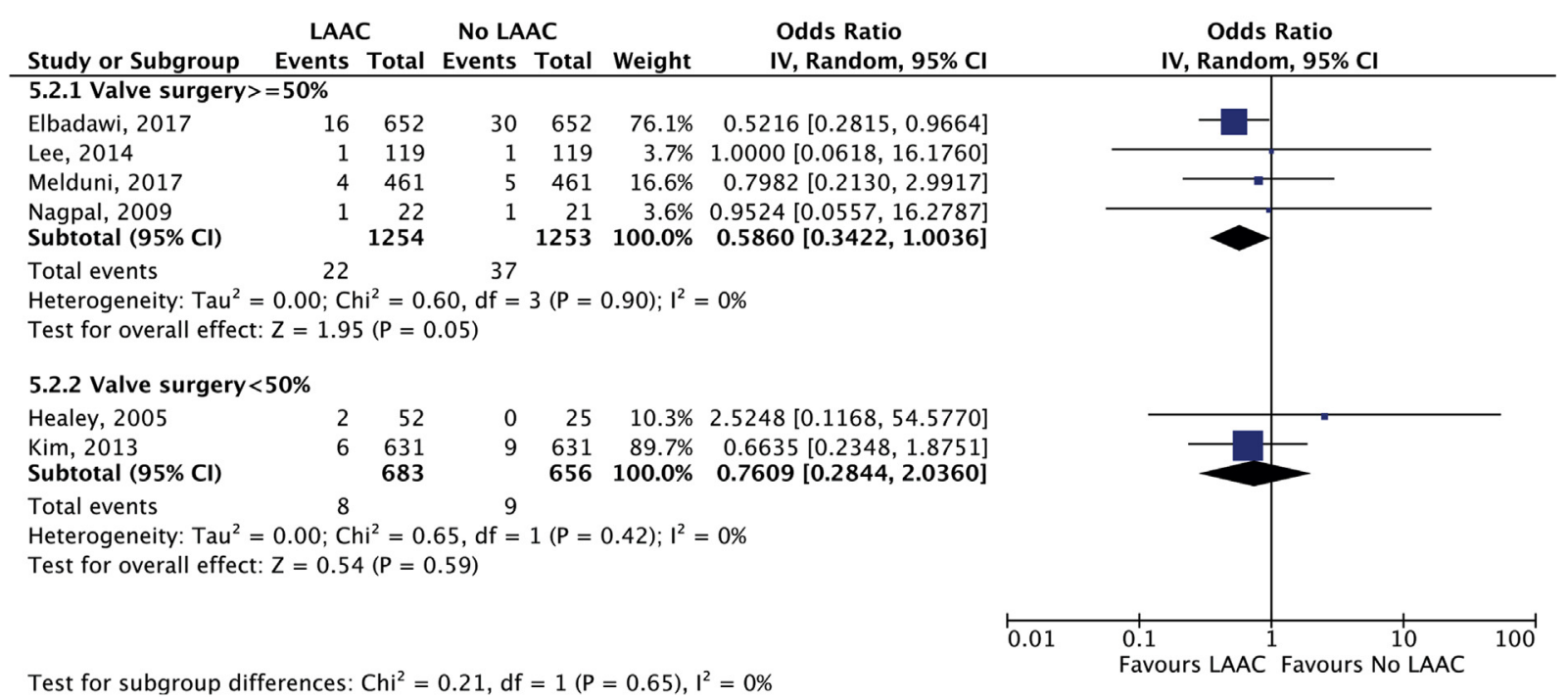

B

FIGURE 3. Thirty-day or in-hospital CVA in randomized trials and matching studies, stratified by preoperative AF status (A) and valve surgery (B). LAAC, Left atrial appendage closure; $I V$, inverse variance; $C I$, confidence interval; $A F$, atrial fibrillation.

\section{Stratified Meta-Analysis}

Figure 3, A, shows the short-term CVA risk stratified by preoperative AF dominance, and Figure $3, B$, shows the same risk stratified by valve surgery dominance. The benefit of LAAC on the risk of CVA was more evident in the preoperative AF strata (OR, 0.538, 95\% CI, 0.295-0.982). This tendency was also observed in valve surgery dominant strata (OR, 0.586, 95\% CI, 0.342-1.004), but not in the non-AF or nonvalve surgery stratas (Figure $3, A$ and $B$ ).

\section{Influence of Each Study on Summary Estimates}

Influences of each study on the summary ORs are reported in Tables 2 and 3. Table 2 shows the results for 30-day or in-hospital mortality, indicating that the association between LAAC and lower mortality was robust even with removal of 1 of 3 studies included. Table 3 shows the results for 30-day or in-hospital CVA; the maximum upper limit of $95 \%$ CI was 1.66 when the study from Elbadawi and colleagues ${ }^{11}$ was excluded. 
TABLE 2. Influence of each study on 30-day or in-hospital mortality

\begin{tabular}{|c|c|c|c|}
\hline Study omitted & $\begin{array}{c}\text { Summary } \\
\text { OR }\end{array}$ & $\begin{array}{c}\text { Lower limit } \\
\text { of } 95 \% \text { CI }\end{array}$ & $\begin{array}{l}\text { Upper limit } \\
\text { of } 95 \% \text { CI }\end{array}$ \\
\hline Elbadawi, $2017^{11}$ & 0.478 & 0.240 & 0.952 \\
\hline Melduni, $2017^{12}$ & 0.303 & 0.150 & 0.611 \\
\hline Lee, $2014^{13}$ & 0.385 & 0.233 & 0.637 \\
\hline Combined & 0.384 & 0.233 & 0.631 \\
\hline
\end{tabular}

$O R$, Odds ratio; $C I$, confidence interval.

\section{Evaluation of Publication Bias}

Finally, the potential impact of publication bias on 30-day or in-hospital CVA was assessed (Figures E1 and E2). Although the number of studies is limited, the Funnel plot did not show significant asymmetry. Begg's test for small study effects did not suggest significant publication bias either $(P=.462)$. Egger's plot is shown in Figures E1 and E2, reporting a possible publication bias $(P=.027)$.

\section{Outcomes in Observational Studies}

Table 4 demonstrates the study characteristics of unadjusted observational studies that were excluded from the main analysis. Because the adjusted effect estimates on short-term mortality or CVA were not available in these studies, the crude effect estimates on mortality and CVA from these studies are shown in Figure 4, $A$ and $B$, pooled separately from the main analysis. Both of these indicate no significant results. The risk of bias analysis on all the observational studies is shown in Table E2.

\section{DISCUSSION}

The present study is the first comprehensive systematic review and meta-analysis of the impact of concomitant surgical LAAC at the time of cardiac surgery, including patients with and without $\mathrm{AF}$ and those undergoing all types of procedures. Of note, all the studies included in the main analysis were RCTs or matching studies affording less bias than unadjusted retrospective cohort studies. Our main

TABLE 3. Influence of each study on 30-day or in-hospital cerebrovascular accident

\begin{tabular}{|c|c|c|c|}
\hline Study omitted & $\begin{array}{c}\text { Summary } \\
\text { OR }\end{array}$ & $\begin{array}{c}\text { Lower limit } \\
\text { of } 95 \% \text { CI }\end{array}$ & $\begin{array}{l}\text { Upper limit } \\
\text { of } 95 \% \text { CI }\end{array}$ \\
\hline Elbadawi, $2017^{11}$ & 0.799 & 0.384 & 1.664 \\
\hline Melduni, $2017^{12}$ & 0.600 & 0.362 & 0.995 \\
\hline Lee, $2014^{13}$ & 0.614 & 0.380 & 0.991 \\
\hline Kim, $2013^{14}$ & 0.612 & 0.360 & 1.040 \\
\hline Nagpal, $2009^{16}$ & 0.615 & 0.381 & 0.992 \\
\hline Healey, $2005^{17}$ & 0.602 & 0.373 & 0.970 \\
\hline Combined & 0.622 & 0.388 & 0.998 \\
\hline
\end{tabular}

$O R$, Odds ratio; $C I$, confidence interval. findings were an association between LAAC and superior 30-day or in-hospital mortality and lower incidence of CVA (Figure 2, $A$ and $B$ ). This association was especially obvious among those in AF preoperatively, and a similar tendency was observed among those undergoing valve surgery (Figure 3, $A$ and $B$ ). These data support a practice of LAAC among these subsets of patients undergoing cardiac surgery.

Although routine LAAC has been advocated by some, the evidence base for its actual benefit remains limited and somewhat conflicting. According to the American Heart Association/American College of Cardiology/Heart Rhythm Society guideline, surgical LAAC is classified as class IIb with level of evidence C. ${ }^{25}$ Although we were able to include 3 RCTs in the present meta-analysis, ${ }^{15-17}$ all were small studies with less than 100 patients included and accordingly had insufficient power to detect differences in rare events such as death or CVA. Three PSM studies and 1 case-matching study were included in our study. The most recently published and largest PSM study by Melduni and colleagues ${ }^{12}$ included only 461 matching pairs. Their median follow-up was 9.1 years. They failed to identify any statistically significant difference in long-term mortality or stroke rates, but significantly higher rates of early postoperative $\mathrm{AF}$ in the LAAC group $(68.6 \%$ vs $31.9 \%, P<.001)$ suggesting a risk of sorts associated with the procedure. Reassuringly, the 30-day mortality trended lower in the LAAC group $(2.5 \%$ vs $5.2 \%, P=.12)$. The 30 -day stroke was similar between groups $(0.9 \%$ vs $1.0 \%, P=.22)$. Of note in their study, a history of AF was seen in less than half patients in both groups ( $45 \%$ vs $47 \%, P=.51$ ), although more than $95 \%$ of patients in both groups underwent valve surgery. In contrast to Melduni and colleagues' findings, ${ }^{12}$ a recent case-matching study by Elbadawi and colleagues ${ }^{11}$ showed a significant short-term benefit of LAAC. They queried the Nationwide Inpatients Sample Database from 1998 to 2013 for those who had AF and underwent valve surgery and created 652 matched pairs by a case-control matching based on the CHA2DS2VASc score. They observed that LAAC was significantly associated with lower incidence of in-hospital CVA $(2.5 \%$ vs $4.6 \%, P=.04)$ and death $(1.5 \%$ vs $4.9 \%, P=.001)$. Two other PSM studies were also included in our analysis, one by Lee and colleagues ${ }^{13}$ and one by Kim and colleagues. ${ }^{14}$ Lee and colleagues ${ }^{13}$ matched preoperative status including AF history in those undergoing surgical ablation for $\mathrm{AF}$ and found no significant change in mortality or stroke rate. Kim and colleagues ${ }^{14}$ conducted PSM in those undergoing CABG or valve surgery without matching preoperative AF status and reported similar postoperative CVA between the LAAC and non-LAAC groups ( $1 \%$ vs $1 \%, P=.44)$. Among those with postoperative AF, however, CVA was significantly lower in the LAAC group $(0 \%$ vs $6 \%$, 
TABLE 4. Study characteristics of unadjusted studies excluded from the main analysis

\begin{tabular}{cccccc}
\hline & \multicolumn{5}{c}{ LAAC Non-LAAC } \\
Author, year & Country & No. & No. & Population & LAAC technique \\
\hline Wilbring, $2016^{19}$ & Germany & 240 & 158 & $\begin{array}{c}\text { Open surgery } \\
\text { for permanent }\end{array}$ & Amputation \\
& & & & AF &
\end{tabular}

\section{Main results associated with the current}

Prospective registry enrolled patients with permanent AF undergoing cardiac surgery. In-hospital death and mortality/thromboembolic events at $1 \mathrm{y}$ were evaluated in the following 4 groups: group I: only surgical ablation, group II: only LAAC, group III: surgical ablation and LAAC, group IV: no surgical ablation or LAAC. Crude OR for in-hospital death was 0.95 (95\% CI, 0.40-2.27) in the LAAC group compared with the non-LAAC group, and those for mortality and thromboembolic event at $1 \mathrm{y}$ were 0.70 (95\% CI, 0.39-1.24) and 0.41 (95\% CI, 0.21-0.82), respectively.

\begin{tabular}{|c|c|c|c|c|c|}
\hline Min, $2016^{20}$ & China & 81 & 92 & $\begin{array}{l}\text { MVR for those } \\
\text { with AF }\end{array}$ & $\begin{array}{l}\text { Endocardial } \\
\text { suture }\end{array}$ \\
\hline Kato, $2015^{5}$ & Japan & 369 & 1462 & Open surgery & $\begin{array}{l}\text { Amputation } \\
\text { Ligation }\end{array}$ \\
\hline
\end{tabular}

Retrospective study enrolled 173 subjects with AF undergoing bioprosthetic MVR. The main outcome of interest was postoperative thromboembolic events. During the mean follow-up time of $40 \pm 17 \mathrm{mo}$, crude OR for late thromboembolic event was 1.15 (95\% CI, 0.45-2.93).

Prospective observational study of 1831 patients undergoing cardiac surgery. The incidence of inhospital mortality and postoperative CVA within $6 \mathrm{mo}$ in patients with and without LAAC was compared. Crude OR for in-hospital death was 0.96 (95\% CI, $0.42-2.20$ ), and adjusted OR for CVA at 6 mo was 1.07 (95\% CI, 0.54-1.97).

\begin{tabular}{|c|c|c|c|c|c|}
\hline Kurfirst, $2015^{21}$ & Czech & 140 & 459 & $\begin{array}{l}\text { Open surgery } \\
\text { with ablation } \\
\text { for AF }\end{array}$ & Amputation \\
\hline Zapolanski, $2013^{22}$ & United States & 808 & 969 & Open surgery & $\begin{array}{l}\text { Double } \\
\text { ligation }\end{array}$ \\
\hline
\end{tabular}

Retrospective analysis made of 599 patients who underwent surgical myocardial revascularization or valve surgery with concomitant surgical ablation of AF. TIA/CVA events were compared postoperatively and at $30 \mathrm{~d}$ and $1 \mathrm{y}$. Crude ORs for 30-d mortality and TIA/CVA were 0.69 (95\% CI, 0.29-1.57) and 0.50 (95\% CI, 0.11-2.23). Crude ORs for 1-y mortality and TIA/CVA were 0.53 (95\% CI, 0.24-1.15) and 0.87 (95\% CI, 0.28-2.67).

Retrospective analysis of the patients who received open surgery with and without LAAC. In-hospital CVA and 30-d mortality were compared between groups. LAA was successfully excluded in $53(94.7 \%)$ of the 56 patients who underwent postoperative transesophageal echocardiography. Crude ORs for 30-d mortality and CVA were $0.29(95 \% \mathrm{CI}$, $0.12-0.72$ ) and 0.52 (95\% CI, 0.21-1.27), respectively.

\begin{tabular}{|c|c|c|c|c|c|c|}
\hline $\begin{array}{l}\text { García-Fernández, } \\
2003^{23}\end{array}$ & Spain & 58 & 147 & MVR & Ligation & $\begin{array}{l}\text { Retrospective study analyzed } 205 \text { patients with previous } \\
\text { MVR and referred for echocardiography study. The } \\
\text { main outcome measure was the occurrence of a } \\
\text { thromboembolic event. LAAC was performed in } 58 \\
\text { patients, but closure success rate by echocardiography } \\
\text { was } 89.7 \% \text {. During median time from MVR to } \\
\text { echocardiography study of } 69.4 \text { mo, } 2 \text { patients in the } \\
\text { LAAC group and } 25 \text { patients in the non-LAAC group } \\
\text { had an embolism. Adjusted OR for thromboembolic } \\
\text { event was } 0.15 \text { ( } 95 \% \text { CI, } 0.032-0.67) \text {. }\end{array}$ \\
\hline
\end{tabular}

(Continued) 
TABLE 4. Continued

\begin{tabular}{ccccccc}
\hline Author, year & Country & No. & No. & Population & LAAC technique & \multicolumn{2}{c}{$\begin{array}{c}\text { Main results associated with the current } \\
\text { meta-analysis }\end{array}$} \\
\hline Bando, $2003^{24}$ & Japan & 493 & 319 & $\begin{array}{c}\text { Mechanical } \\
\text { MVR }\end{array}$ & Not specified & $\begin{array}{c}\text { Retrospective analysis of the patients undergoing } \\
\text { mechanical MVR. LAAC was performed in } 493 \\
\text { patients. All patients were observed for at least } 6 \text { mo } \\
\text { after their operations. Late stroke occurred in } 72\end{array}$ \\
& & & & & patients, and crude OR for late stroke was $1.24(95 \%$ \\
& & & & & CI, 0.75-2.06).
\end{tabular}

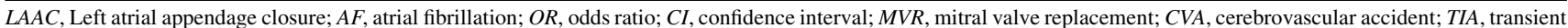
ischemic attack.

$P=.003)$. It is unfortunate that they did not clearly mention the preoperative AF status in both groups, making it unclear whether LAAC contributed to lower CVA or not in this setting.

Because of the power limitations of such studies of what are now fortunately uncommon events, the present meta-analysis is worthwhile in that it clarified the association between LAAC and reduced risk of short-term mortality and CVA. We were able to find 1 preceding meta-analysis published by Tsai and colleagues ${ }^{18}$ on this topic, including 7 studies with 3653 patients, and they concluded LAAC was significantly associated with decreased stroke and mortality rate, which is compatible with our results. However, their pooled estimates calculation relied heavily on large observational studies subject to significant bias. For example, in calculating pooled risk ratios for 30-day stroke, they included only 3 studies and weighted $89.7 \%$ on the unmatched crude cohorts in Kim and colleagues' report. ${ }^{14}$ This suggests their summary estimate might not be free from bias. They also did not assess how preoperative AF status would affect the effect of LAAC on the outcomes. In this sense, our meta-analysis would be different from the preceding one for the following 2 standpoints: (1) Our analysis included 2 additional updated studies, and all the unadjusted retrospective studies ${ }^{5,19-24}$ were excluded from the main analysis; and (2) we included both preoperative AF dominant and nondominant studies (Table 1), which enabled us to conduct the stratified analysis to discern the benefit of LAAC separately, revealing the benefit would be more apparent in AF dominant strata (Figure 3, A). Of note, the $\mathrm{I}^{2}$ statistics in all the Forest plots in the current study were minimal, indicating there was little heterogeneity across the studies included.

We also performed an influential analysis to see the robustness of our pooled estimates (Tables 2 and 3). Although our result on short-term mortality did not depend too much on any 1 of the studies included, the most influential study on short-term CVA was the case-matching study by Elbadawi and colleagues. ${ }^{11}$ Given that their population basically comprised patients with $\mathrm{AF}$ who underwent valve surgery, we should be prudent in the

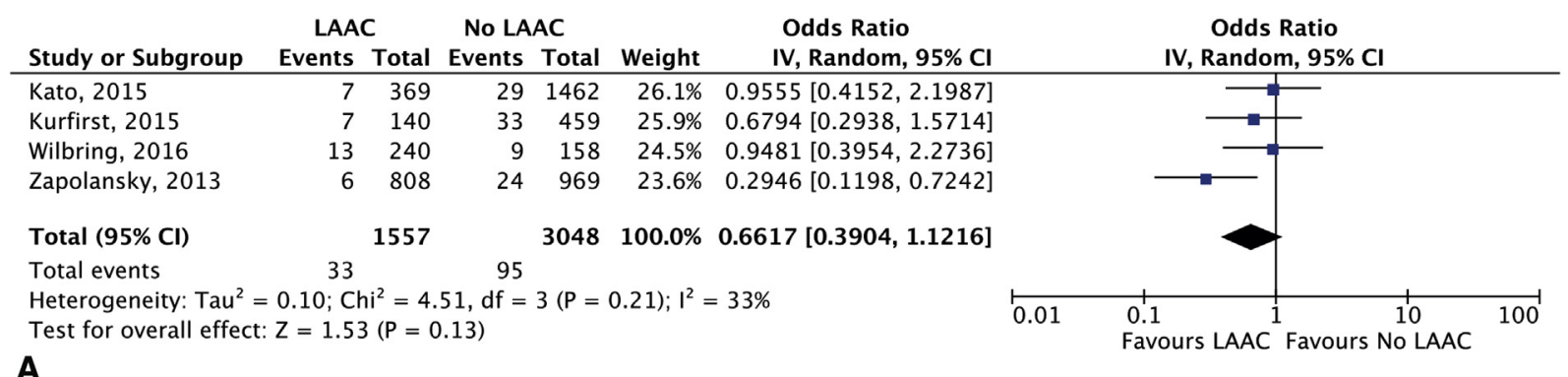

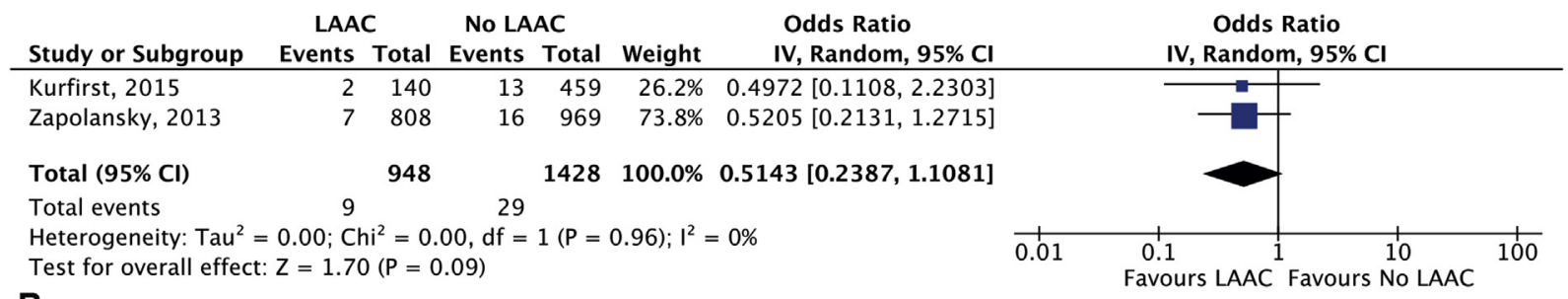

FIGURE 4. Thirty-day or in-hospital mortality (A) and CVA (B) in unadjusted observational studies. LAAC, Left atrial appendage closure; $I V$, inverse variance; $C I$, confidence interval. 
interpretation of our results, implying that surgical LAAC might not provide as great benefits in non-AF and nonvalvular cases.

Another important aspect that should be addressed is anticoagulation therapy after surgical LAAC. It is possible that the lower short-term mortality in the LAAC group could be due to a lower CVA rate or alternatively fewer bleeding complications because of avoiding aggressive anticoagulation after LAAC. Unfortunately, there were few studies available that investigated this issue in detail. The long-term PSM study by Melduni and colleagues ${ }^{12}$ did not include any information on anticoagulation therapy during follow-up. Lee and colleagues ${ }^{13}$ reported that the anticoagulation rate in the late period did not change significantly between groups $(62.2 \%$ in LAAC vs $55.4 \%$ in the non-LAAC group, $P=.29$ ) and reported that no significant differences were found in late survival and CVA rates. Thus, in contrast to percutaneous LAAC, we still do not have much evidence on surgical LAAC and whether the procedure could be an alternative to lifelong anticoagulation or not. To clarify this point, we need more prospective trials with long-term follow-up.

Other factors that might have affected the results would be variations in surgical techniques of LAAC and the addition of concurrent ablation. Regarding the former, a recent study reported a residual communication between LAA and left atrium was seen within 30 days after surgery in $37 \%$ of patients who underwent surgical LAAC, with the failure rate higher in suture closure than amputation or stapler. $^{26}$ Conversely, another randomized study demonstrated early closure failure rate was highest in stapler exclusion (failure rate $60 \%$ ), compared with $13 \%$ in internal ligation and $20 \%$ in surgical excision $(P=.06) .{ }^{27}$ Reviewing a number of studies, Healey and colleagues ${ }^{17}$ commented that the failure rate was lower in stapler exclusion than suture closure alone ( $28 \%$ vs $55 \%$, $P=.14)$. Available information on surgical LAAC techniques in the studies included in our analysis is summarized in Table 1. We were unable to evaluate how closure technique or its success rate might have affected our pooled estimates, however, because Elbadawi and colleagues $^{11}$ did not include detailed LAAC technique information, and Nagpal and colleagues ${ }^{16}$ focused on mitral surgery and they performed endocardial closure but did not check a residual communication. LAAC techniques in the other 5 studies are mixed with ligation, amputation, and stapler closure, and the rate of complete closure was not necessarily reported. For these reasons, how closure techniques of LAAC affected our results is still unclear.

Regarding the effect of ablation, among the 7 studies included, only the study by Lee and colleagues ${ }^{13}$ focused on those who received concurrent ablation, and the other 6 studies did not. Melduni and colleagues ${ }^{12}$ clearly stated that they excluded those who underwent Maze or pulmonary vein isolation, and Elbadawi and colleagues ${ }^{11}$ reported only $14.4 \%$ of their matched cohorts underwent Maze surgery. In reviewing their data, we found a possible differential impact of LAAC on the outcomes. Although surgical LAAC did not provide any significant benefits in Lee and colleagues' study ${ }^{13}$ that focused on ablation cohorts with mitral valve surgery, the benefit of LAAC was more evident in Elbadawi and colleagues' study, ${ }^{11}$ in which more than $80 \%$ of patients did not receive the Maze procedure. Given these data, the influence of LAAC might be less in those undergoing $\mathrm{AF}$ ablation than those not undergoing $\mathrm{AF}$ ablation.

Finally, we should address potential selection bias in the LAAC group. Better outcomes in the LAAC group also can be explained by subtle selection bias, conducting LAAC in healthier patients rather than sicker patients to minimize invasion. In some cohort studies without randomization or matching, which were not included in our analysis, LAAC was performed in relatively younger patients with less comorbidities such as hypertension or diabetes, ${ }^{5}$ indicating even after matching there still might be a residual confounders.

\section{Study Limitations}

This study presents the following limitations. First, because only 2 of 7 studies in our current analysis conducted long-term time-to-event analysis, our analysis could investigate only short-term outcomes, and the actual effect of LAAC on long-term mortality or CVA rates remains unclear. Second, because most of the studies included in our analysis did not provide detailed information on postoperative anticoagulation management, which could also affect mortality and CVA events after LAAC, we were not able to evaluate how anticoagulation therapy after LAAC would affect the efficacy of surgical LAAC. Third, because of limited information regarding preoperative AF status (persistent or paroxysmal) in each study and the heterogeneous nature of the studies included, the impact of other possible thrombogenic factors, such as heart rhythm at surgery, ablation, valve prosthesis, LAAC technique, or successful closure rate, that might have affected the outcomes is not fully clarified.

\section{CONCLUSIONS}

Despite these limitations, the current study demonstrated better short-term mortality and CVA rates in the LAAC group, especially in preoperative AF dominant strata, and accordingly supports LAAC in this subgroup of patients. However, the efficacy of concomitant surgical LAAC in non-AF and nonvalvular cases and its long-term benefit still remain to be clarified. Our findings should encourage further prospective investigations on this procedure. 


\section{Conflict of Interest Statement}

Authors have nothing to disclose with regard to commercial support.

\section{References}

1. Reddy VY, Sievert H, Halperin J, Doshi SK, Buchbinder M, Neuzil P, et al Percutaneous left atrial appendage closure vs warfarin for atrial fibrillation: a randomized clinical trial. JAMA. 2014;312:1988-98.

2. Lakkireddy D, Afzal MR, Lee RJ, Nagaraj H, Tschopp D, Gidney B, et al Short and long-term outcomes of percutaneous left atrial appendage suture ligation: results from a US multicenter evaluation. Heart Rhythm. 2016;13: 1030-6.

3. Holmes DR, Doshi SK, Kar S, Price MJ, Sanchez JM, Sievert H, et al Left atrial appendage closure as an alternative to warfarin for stroke prevention in atrial fibrillation: a patient-level meta-analysis. J Am Coll Cardiol. 2015;65:2614-23.

4. Holmes DR Jr, Kar S, Price MJ, Whisenant B, Sievert H, Doshi SK, et al Prospective randomized evaluation of the Watchman Left Atrial Appendage Closure device in patients with atrial fibrillation versus long-term warfarin therapy: the PREVAIL trial. J Am Coll Cardiol. 2014;64:1-12.

5. Kato TS, Iwamura T, Endo D, Yokoyama Y, Oishi A, Shimada A, et al. Left atrial appendage closure reduces the incidence of postoperative cerebrovascular accident in patients undergoing cardiac surgery. Circ J. 2015;79:2591-7.

6. Salzberg SP, Plass A, Emmert MY, Desbiolles L, Alkadhi H, Grunenfelder J, et al Left atrial appendage clip occlusion: early clinical results. J Thorac Cardiovasc Surg. 2010;139:1269-74.

7. Khan J, Khan N, Loisa E, Sutinen J, Laurikka J. Increasing occurrence of postoperative atrial fibrillation in contemporary cardiac surgery. $J$ Cardiothorac Vasc Anesth. 2016:30:1302-7.

8. Schnabel RB, Yin X, Gona P, Larson MG, Beiser AS, McManus DD, et al. 50 year trends in atrial fibrillation prevalence, incidence, risk factors, and mortality in the Framingham Heart Study: a cohort study. Lancet. 2015;386:154-62.

9. Moher D, Liberati A, Tetzlaff J, Altman DG, Group P. Preferred reporting items for systematic reviews and meta-analyses: the PRISMA statement. Int J Surg. 2010;8:336-41.

10. Stroup DF, Berlin JA, Morton SC, Olkin I, Williamson GD, Rennie D, et al. Meta-analysis of observational studies in epidemiology: a proposal for reporting. Meta-analysis Of Observational Studies in Epidemiology (MOOSE) group. JAMA. 2000;283:2008-12.

11. Elbadawi A, Olorunfemi O, Ogunbayo GO, Saad M, Elgendy IY, Arif Z, et al Cardiovascular outcomes with surgical left atrial appendage exclusion in patients with atrial fibrillation who underwent valvular heart surgery (from the National Inpatient Sample Database). Am J Cardiol. 2017;119:2056-60.

12. Melduni RM, Schaff HV, Lee HC, Gersh BJ, Noseworthy PA, Bailey KR, et al Impact of left atrial appendage closure during cardiac surgery on the occurrence of early postoperative atrial fibrillation, stroke, and mortality: a propensity score-matched analysis of 10633 patients. Circulation. 2017;135:366-78.

13. Lee CH, Kim JB, Jung SH, Choo SJ, Chung CH, Lee JW. Left atrial appendage resection versus preservation during the surgical ablation of atrial fibrillation. Ann Thorac Surg. 2014;97:124-32.
14. Kim R, Baumgartner N, Clements J. Routine left atrial appendage ligation during cardiac surgery may prevent postoperative atrial fibrillation-related cerebrovascular accident. J Thorac Cardiovasc Surg. 2013;145:582-9.

15. Whitlock RP, Vincent J, Blackall MH, Hirsh J, Fremes S, Novick R, et al. Left atrial appendage occlusion study II (LAAOS II). Can J Cardiol. 2013;29:1443-7.

16. Nagpal AD, Torracca L, Fumero A, Denti P, Cioni M, Alfieri O. Concurrent prophylactic left atrial appendage exclusion: results from a randomized controlled trial pilot study. Eur J Cardiothorac Surg. 2009;36:553-7.

17. Healey JS, Crystal E, Lamy A, Teoh K, Semelhago L, Hohnloser SH, et al. Left Atrial Appendage Occlusion Study (LAAOS): results of a randomized controlled pilot study of left atrial appendage occlusion during coronary bypass surgery in patients at risk for stroke. Am Heart J. 2005;150:288-93.

18. Tsai YC, Phan K, Munkholm-Larsen S, Tian DH, La Meir M, Yan TD. Surgical left atrial appendage occlusion during cardiac surgery for patients with atrial fibrillation: a meta-analysis. Eur J Cardiothorac Surg. 2015;47:847-54.

19. Wilbring M, Jung F, Weber C, Matschke K, Knaut M. Reduced incidence of thromboembolic events after surgical closure of left atrial appendage in patients with atrial fibrillation. Innovations (Philadelphia, Pa). 2016;11:24-30.

20. Min XP, Zhu TY, Han J, Li Y, Meng X. Left atrial appendage obliteration in atrial fibrillation patients undergoing bioprosthetic mitral valve replacement. Herz. 2016;41:87-94

21. Kurfirst V, Kuta B, Canádyová J, Mokráček A. Clinical impact of left atrial appendage resection versus preservation during surgical ablation of atrial fibrillation. Cor et Vasa. 2015;57:e176-80.

22. Zapolanski A, Johnson CK, Dardashti O, O'Keefe RM, Rioux N, Ferrari G, et al Epicardial surgical ligation of the left atrial appendage is safe, reproducible, and effective by transesophageal echocardiographic follow-up. Innovations (Philadelphia, Pa). 2013;8:371-5.

23. García-Fernández MA, Pérez-David E, Quiles J, Peralta J, García-Rojas I, Bermejo J, et al. Role of left atrial appendage obliteration in stroke reduction in patients with mitral valve prosthesis: a transesophageal echocardiographic study. J Am Coll Cardiol. 2003;42:1253-8.

24. Bando K, Kobayashi J, Hirata M, Satoh T, Niwaya K, Tagusari O, et al. Early and late stroke after mitral valve replacement with a mechanical prosthesis: risk factor analysis of a 24-year experience. J Thorac Cardiovasc Surg. 2003;126: 358-64.

25. January CT, Wann LS, Alpert JS, Calkins H, Cigarroa JE, Cleveland JC Jr, et al 2014 AHA/ACC/HRS guideline for the management of patients with atria fibrillation: executive summary: a report of the American College of Cardiology/American Heart Association Task Force on practice guidelines and the Heart Rhythm Society. Circulation. 2014;130:2071-104.

26. Cullen MW, Stulak JM, Li Z, Powell BD, White RD, Ammash NM, et al. Left atrial appendage patency at cardioversion after surgical left atrial appendage intervention. Ann Thorac Surg. 2016;101:675-81.

27. Lee R, Vassallo P, Kruse J, Malaisrie SC, Rigolin V, Andrei AC, et al. A randomized, prospective pilot comparison of 3 atrial appendage elimination techniques: internal ligation, stapled excision, and surgical excision. J Thorac Cardiovasc Surg. 2016;152:1075-80.

Key Words: left atrial appendage closure, atrial fibrillation, meta-analysis, outcome 


\section{APPENDIX. SUPPLEMENTARY DATA Supplemental Methods}

A literature search was performed by using Ovid Medline (PubMed), Embase, and Cochrane Central Register of Controlled Trials databases for studies published from their date of inception to December 2016. We used the following searching codes in each database:

For PubMed:

("Cardiac surgical procedures"[Mesh] OR cardiac surgery[tiab] OR heart surgery[tiab] OR surgical[tiab]) AND (left atrial appendage[tiab]) AND (ligation[tiab] OR occlusion[tiab] $\mathrm{O}$ amputation[tiab] OR exclusion[tiab] OR resection[tiab] OR obliteration[tiab] OR closure[tiab]).
For Embase:

'heart surgery'/de OR 'cardiac surgery'/exp OR 'open heart surgery'/ exp OR 'surgical'/exp

AND 'heart atrium appendage'/de OR 'left atrial appendage'/exp OR 'left atrial appendage':ab,ti

AND 'ligation':ab,ti OR 'occlusion' : ab,ti OR 'amputation' :ab,ti OR 'exclusion':ab,ti OR 'resection':ab,ti OR 'obliteration':ab,ti OR 'closure':ab,ti

For Cochrane Central Register of Controlled Clinical Trials:

((heart OR cardiac) N1 (surgery OR surgical)) AND (((ligation) OR (occlusion) OR (amputation) OR (exclusion) OR (resection) OR (obliteration) OR (closure)) N1 (appendage)) 


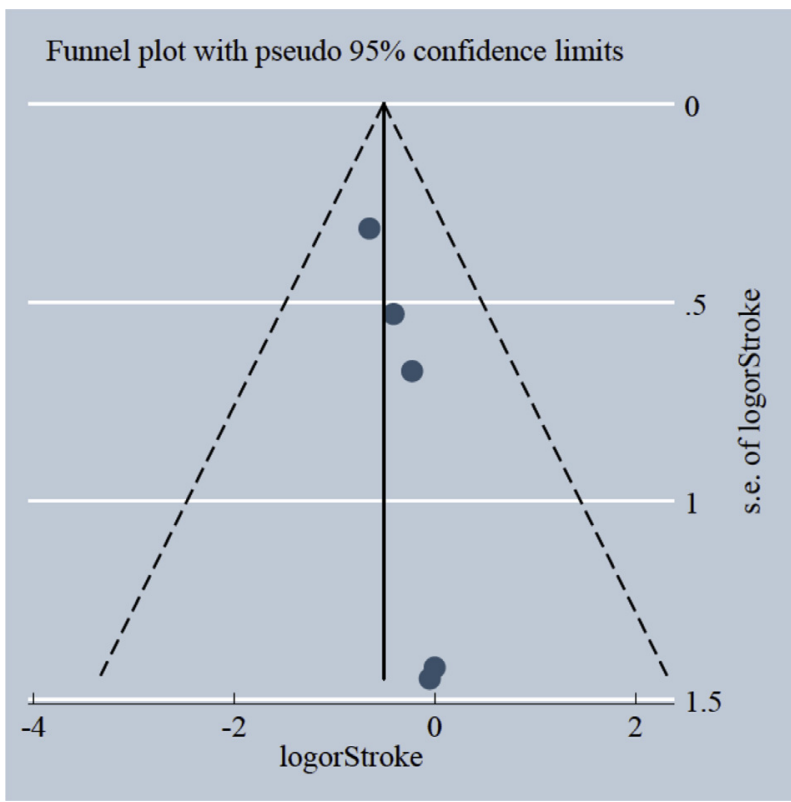

FIGURE E1. Funnel plot for 30-day or in-hospital CVA.

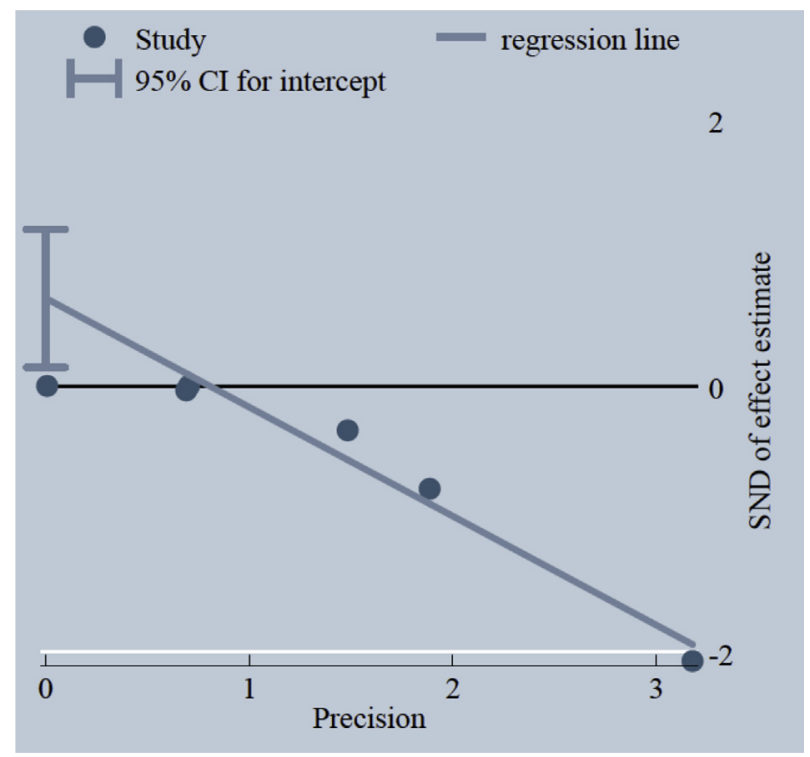

FIGURE E2. Egger's graph for 30-day or in-hospital CVA. CI, Confidence interval.

TABLE E1. Log odds ratio and standard errors of the outcomes in each study included

\begin{tabular}{|c|c|c|c|c|}
\hline \multirow[b]{2}{*}{ Study } & \multicolumn{2}{|c|}{ 30-d or in-hospital mortality } & \multicolumn{2}{|c|}{ 30-d or in-hospital CVA } \\
\hline & Log OR & $\mathbf{S E}$ & Log OR & SE \\
\hline Elbadawi, $2017^{11}$ & -1.198 & 0.3666 & -0.6509 & 0.3147 \\
\hline Melduni, $2017^{12}$ & -0.7202 & 0.3599 & -0.2253 & 0.6741 \\
\hline Lee, $2014^{13}$ & -1.1070 & 1.6381 & 0.0000 & 1.4202 \\
\hline Kim, $2013^{14}$ & - & - & -0.4103 & 0.5301 \\
\hline Nagpal, $2009^{16}$ & - & - & -0.0488 & 1.4483 \\
\hline Healey, $2005^{17}$ & - & - & 0.9261 & 1.5681 \\
\hline Whitlock, $2013^{15}$ & NA & NA & - & - \\
\hline
\end{tabular}

$C V A$, Cerebrovascular accident; $O R$, odds ratio; $S E$, standard error; $N A$, not available.

TABLE E2. Risk of bias summary in observational studies

\begin{tabular}{|c|c|c|c|c|c|}
\hline \multirow[b]{2}{*}{ First author, $y$} & \multicolumn{5}{|c|}{ Risk of bias } \\
\hline & $\begin{array}{l}\text { Inclusion } \\
\text { in this } \\
\text { meta-analysis }\end{array}$ & $\begin{array}{c}\text { Failure to } \\
\text { develop and apply } \\
\text { appropriate eligibility } \\
\text { criteria }\end{array}$ & $\begin{array}{l}\text { Flawed measurement } \\
\text { of both exposure } \\
\text { and outcome }\end{array}$ & $\begin{array}{c}\text { Failure to } \\
\text { adequately control } \\
\text { confounding }\end{array}$ & $\begin{array}{l}\text { Incomplete } \\
\text { follow-up }\end{array}$ \\
\hline Elbadawi, $2017^{11}$ & Yes & Low & Low & Low & Low \\
\hline Melduni, $2017^{12}$ & Yes & Low & Low & Low & Low \\
\hline Lee, $2014^{13}$ & Yes & Low & Low & Low & Low \\
\hline Kim, $2013^{14}$ & Yes & Low & Low & Low & Low \\
\hline Wilbring, $2016^{19}$ & No & Low & Low & High & Low \\
\hline Min, $2016^{20}$ & No & Low & High & High & High \\
\hline Kato, $2015^{5}$ & No & Low & Low & High & Low \\
\hline Kurfirst, $2015^{21}$ & No & Low & Low & High & Low \\
\hline Zapolanski, $2013^{22}$ & No & Low & Low & High & Low \\
\hline García-Fernández, $2003^{23}$ & No & High & High & High & High \\
\hline Bando, $2003^{24}$ & No & Low & Low & High & High \\
\hline
\end{tabular}

